\title{
Chapter 8 \\ Energy Consumption in Transition: Evidence from Facility-Level Data
}

\author{
Naonari Yajima, Toshi H. Arimura, and Taisuke Sadayuki
}

\begin{abstract}
This chapter estimated the impact of the Tokyo emissions trading scheme (ETS) and Saitama ETS on energy consumption in the manufacturing sector using a facility-level panel data set compiled from the Current Survey of Energy Consumption, a nationwide survey on energy consumption conducted by the Agency for Natural Resources and Energy in Japan. To our knowledge, no study has used this rich data set to perform sophisticated econometric analyses. We found that the Tokyo ETS reduced electricity consumption by $16 \%$. On the other hand, we did not find evidences of switching from dirty fossil fuel to cleaner fuel associated with the introduction of the Tokyo ETS. The impact of the Saitama ETS on energy consumption was not statistically confirmed based on our samples. Additional studies are needed to identify the different impacts of the ETSs between Tokyo and Saitama. We also found that Japan has been experiencing long-term decreasing trends in the number of manufacturing facilities and the volume of fossil fuel consumption, which may reduce Japanese $\mathrm{CO}_{2}$ emissions in the long run.
\end{abstract}

Keywords Emission trading schemes - Tokyo ETS · Saitama ETS • Manufacturing sector

\section{Introduction}

The previous two chapters investigated the impacts of the Tokyo emissions trading scheme (ETS) and the Saitama ETS based on facility-level data. Chapter 6 (Abe

\footnotetext{
N. Yajima $(\bowtie)$

Waseda Institute of Political Economy, Waseda University, 1-6-1 Nishi-waseda, Shinjuku-ku, Tokyo 169-8050, Japan

e-mail: nao.yajima@asagi.waseda.jp

T. H. Arimura

Faculty of Political Science and Economics, Waseda University, 1-6-1 Nishi-waseda, Shinjuku-ku, Tokyo 169-8050, Japan

T. Sadayuki

Faculty of Economics, Seijo University, 6-1-20, Seijo, Setagaya-ku, Tokyo 157-8511, Japan

(C) The Author(s) 2021

T. H. Arimura and S. Matsumoto (eds.), Carbon Pricing in Japan,

Economics, Law, and Institutions in Asia Pacific,

https://doi.org/10.1007/978-981-15-6964-7_8
} 
and Arimura) focused on university buildings and examined the impact of the Tokyo ETS by employing the difference-in-differences approach using the two-way fixed effects model. Chapter 7 (Hamamoto) targeted the facilities of all industries under the Saitama ETS and examined the impact of this ETS by comparing the facilities in Saitama Prefecture and one of its adjunct prefectures with a similar background in terms of environmental policies and industrial structures, namely, Gunma Prefecture.

Despite the similarity between the Tokyo ETS and Saitama ETS, two important distinctions should be noted. The first is the type of major industry targeted under each ETS. Because of the high land price and stringent environmental regulations in Tokyo, commercial and office buildings constitute the majority of regulated facilities under the Tokyo ETS. However, the regulated facilities under the Saitama ETS mostly belong to the manufacturing sector. Commercial and office buildings mainly use electricity, while manufacturing facilities consume various types of fossil fuels, ranging from petroleum-based fuels to non-petroleum-based fuels. Therefore, each regulated facility adopts a different reduction strategy because the cost of compliance with ETSs can differ depending on the type of industry and the type of energy used. Some facilities may reduce emissions by decreasing the usage of electricity, while others may reduce the usage of fossil fuel.

The second difference between the two ETSs is associated with the severity of compliance obligation. Compliance with the emission reduction targets under the Tokyo ETS is mandatory, and facilities that violate the regulation face fines. In contrast, compliance with the Saitama ETS is voluntary in the sense that regulated facilities that do not comply with the ETS face no monetary penalties.

This chapter focuses on the manufacturing sector and examines the impacts of both the Tokyo ETS and Saitama ETS on the consumption of energy by regulated facilities. We utilize the Current Survey of Energy Consumption (CSEC), which includes rich facility-level data from a nationwide survey on energy consumption conducted by the Agency for Natural Resources and Energy in Japan. This survey was started in 1981 with the aim of monitoring the consumption of various energy types by energy-intensive facilities and making use of the data for policy making, especially for policies concerning petroleum consumption. As of 2016, the survey covers approximately 1300 facilities (hereinafter, reporting facilities) in the manufacturing sector. Reporting facilities are required to submit monthly reports on the consumption of various energy types, such as electricity or petroleum.

The contribution of this chapter can be summarized as follows. First, although the previous two chapters investigated the impacts of ETSs on facilities in different prefectures and industries, this chapter examines two local ETSs by focusing on manufacturing facilities. To comply with the ETSs, regulated facilities can reduce their GHG emissions by decreasing their energy use. The Current Survey of Energy Consumption (CSES) allows us to examine this question in the manufacturing sector at the facility level in both Tokyo and Saitama and compare the effectiveness of the two local ETSs. As noted above, the Saitama ETS differs from the Tokyo ETSs because there is no financial penalty for noncompliance. We examine whether the ETS without the financial penalty in Saitama can generate the same level of GHG emission reductions as the Tokyo ETS, which has the binding obligation. 
Second, we examine whether the regulated facilities reduced their emissions by changing the fuel mixture. The CSEC allows us to investigate whether the implementation of ETSs has motivated regulated facilities to shift energy consumption from dirty to cleaner energies. Previous studies on the impact of ETSs in Japan (Arimura and Abe 2020; Wakabayashi and Kimura 2018) only had access to aggregate levels of emissions and/or only the amount of electricity use. In contrast, Wagner et al. (2014) investigated the impacts of the EU ETS on the energy composition of coal, oil, gas, and steam and found that the regulated plants reduced their share of coal by approximately $2 \%$. We follow this line of the study and provide the first empirical evidence regarding the shift in energy composition under the two local ETSs in Japan. Similar to the case of EU ETS, the regulated facilities may try to reduce fossil fuel consumptions such as coal. Another possibility is that they may comply with their target by reduction of fuels with cheaper abatement costs, for instance, electricity.

Finally, to the best of our knowledge, this study is the first to analyze the impacts of Japanese local ETSs using the facility-level data of the CSEC. Because scarce studies use these data, descriptive statistics and simple graphical illustrations can provide valuable information on the current trends of consumption of different energy types by large facilities.

We focus on the reduction of GHG emissions in this chapter. In general, under ETSs, regulated facilities can comply with the regulation either by reducing emissions or by purchasing additional allowances. However, few trades have been performed in the Tokyo and Saitama ETSs as illustrated in Chaps. 6 and 7. Compliance has primarily been achieved by reducing emissions, and many allowances have carried over to the next phase. Therefore, we can safely focus on emission reductions in our analysis.

The next section describes the CSEC data in detail and graphically demonstrates the trends in the number of reporting facilities and consumption by energy type. This data description is followed by an empirical analysis section that focuses on the impact of the Tokyo ETS and Saitama ETS on the consumption of various energy types. The final section concludes with some discussion on the direction of future work.

\section{Data Description ${ }^{1}$}

This section introduces a facility-level survey, the CSEC conducted by the Agency for Natural Resources and Energy in Japan. The survey was started in 1981 with the aim of collecting information on fuel consumption in the energy-intensive manufacturing sector, and it covers the following nine manufacturing industries: the "pulp and paper industry", "chemical industry", "chemical fiber industry", "petroleum products industry", "ceramic, clay and stone products industry", "glass product industry",

\footnotetext{
${ }^{1}$ This section is based on the Agency for Natural Resources and Energy of the Ministry of Economy, Trade and Industry (METI) (2015) "Yearly Report of the Current Survey of Energy Consumption".
} 
"iron and steel industry", "nonferrous metals industry", and "machinery industry" (Table 1). Notably, the electric power and gas industries are not covered by the survey.

Table 1 Reported fuel types

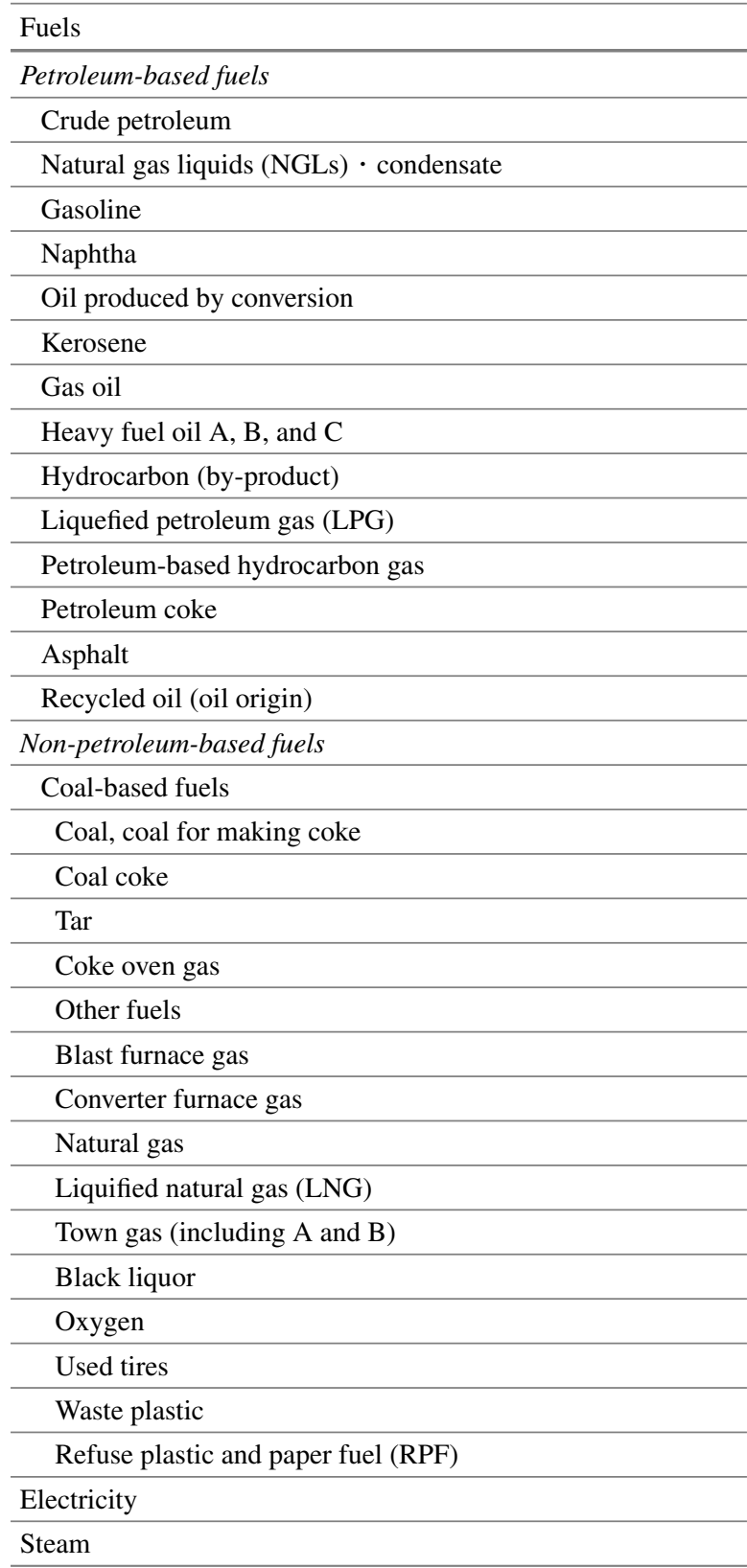


Every facility with more than a designated number of employees (hereinafter, reporting facilities) is required to report its monthly consumption of various energy types. The threshold of the number of employees varies across industries. In some industries, such as the pulp and paper industry, chemical industry or petroleum products industry, all facilities are required to make reports regardless of the number of employees. All facilities in the nonferrous metals industry are also subject to the survey unless the facility produces secondary aluminum ingot. In other industries, facilities with a certain number of employees or more are targeted under the survey. For instance, a facility in the machinery industry, glass product industry or chemical fiber industry is not subject to the survey if it has less than 500 employees, 100 employees or 50 employees, respectively. Facilities with 500 employees or less fall beyond the scope of the survey.

The survey requires reporting facilities to report their consumption of petroleumbased fuels, non-petroleum-based fuels, electricity, and steam on a monthly basis (Table 1). Table 2 lists the number of reporting facilities that appear at least once between FY2004 and FY2015 and the average energy consumption by sector. The number of reporting facilities varied across sectors; for instance, there were 600 reporting facilities from the machinery industry and 50 reporting facilities from the glass product industry. The average energy consumption per facility also varied by sector. For example, the average consumption of electricity was approximately 6000 thousand kWh in the machinery industry and approximately 13,000 thousand $\mathrm{kWh}$ in the pulp and paper industry. On the other hand, the machinery industry consumed approximately 30 tons of liquefied petroleum gas (LPG), while the pulp and paper industry consumed approximately 9 tons of LPG.

In the following sections, we take a closer look at the consumption of several selected fuels and electricity generation by renewable energies and cogeneration.

\section{Overall Trend in Energy-Intensive Sectors}

The overall trends of the number of reporting facilities and the energy consumption by major prefectures are introduced in this section.

Figure 1 shows the number of reporting facilities from 2004 to $2016 .^{2}$ The total number of reporting facilities in Japan diminished from approximately 1600 in 2004

\footnotetext{
${ }^{2}$ For each year, we count the number of facilities that made monthly report(s) at least once during the year. Because some facilities made multiple reports for different sectors, we remove such duplicate observations to compute the number of facilities, and we handle such duplications as follows. If a facility reported the same amount of fuel consumption in two reports, then we take the average over the duplications for each month. The reason is that we do not know the fuel consumption ratio between sectors; therefore, we assume that the value is the total consumption of fuel, with each sector consuming half of the fuel. If a facility reported zero consumption or a missing value in one file and positive consumption in another, then we also take the average over the duplications, assuming that such reports of a positive number are the total consumption of fuels. Finally, if a facility reported different values for each sector, then we keep these values, assuming that they report the actual values for each sector.
} 


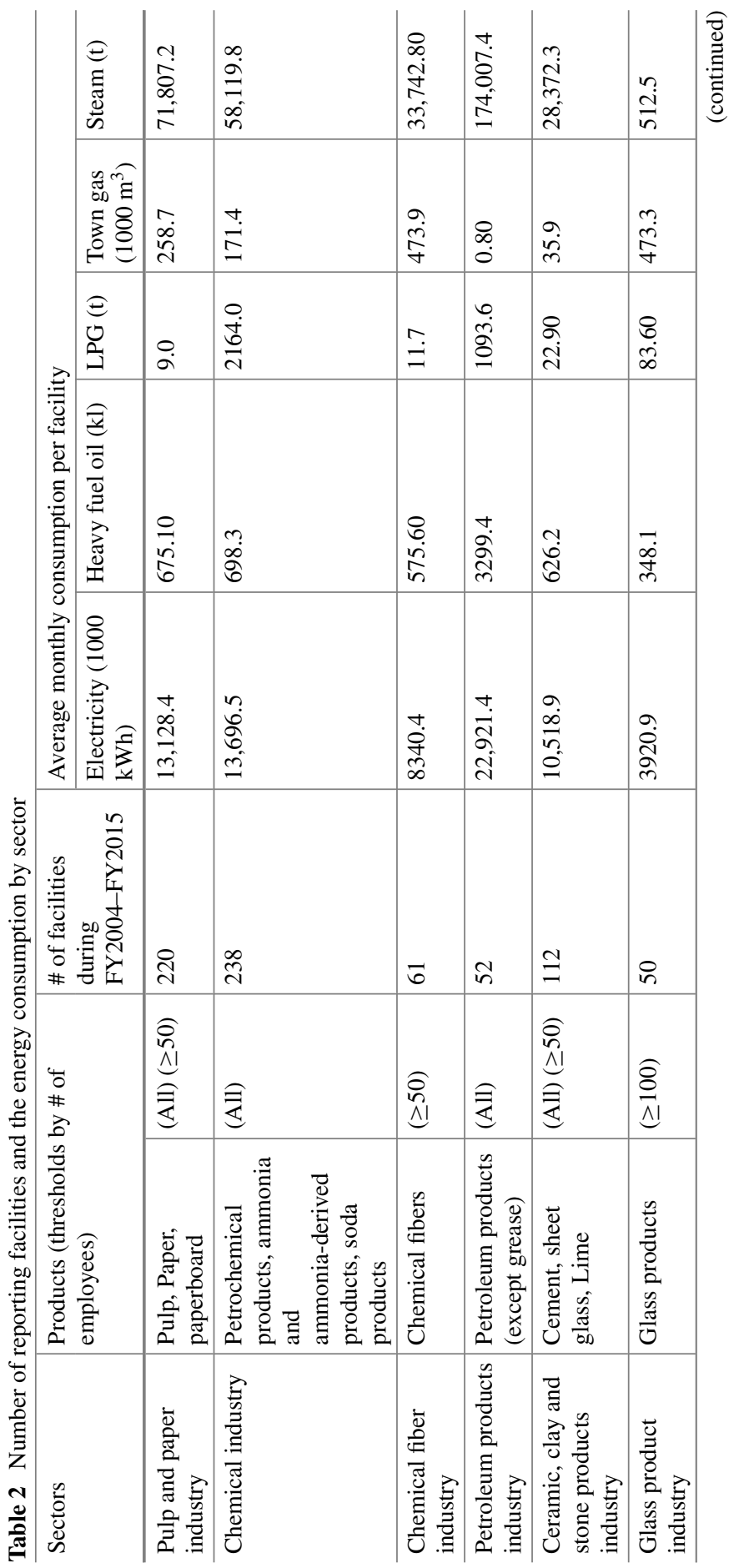


8 Energy Consumption in Transition: Evidence ...

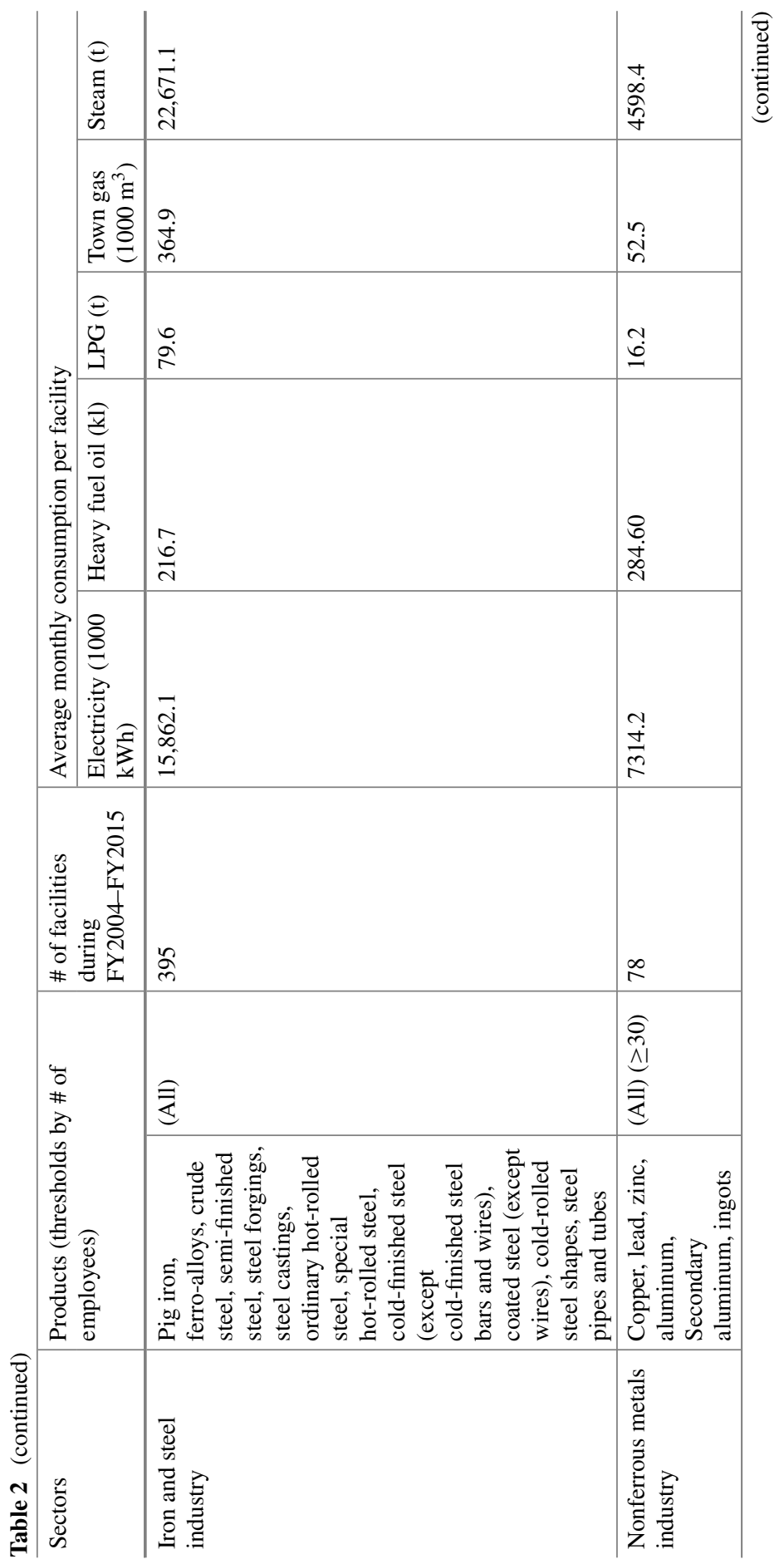




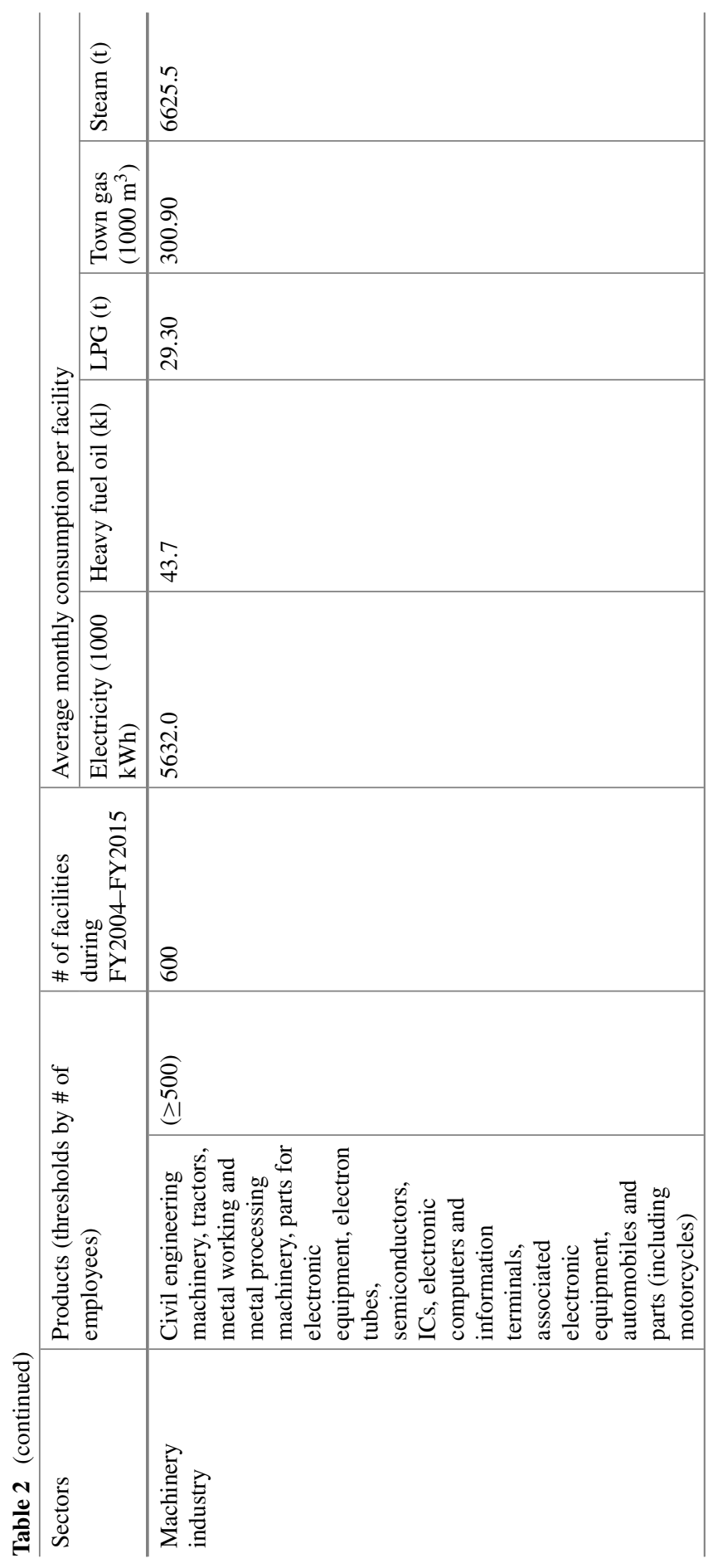




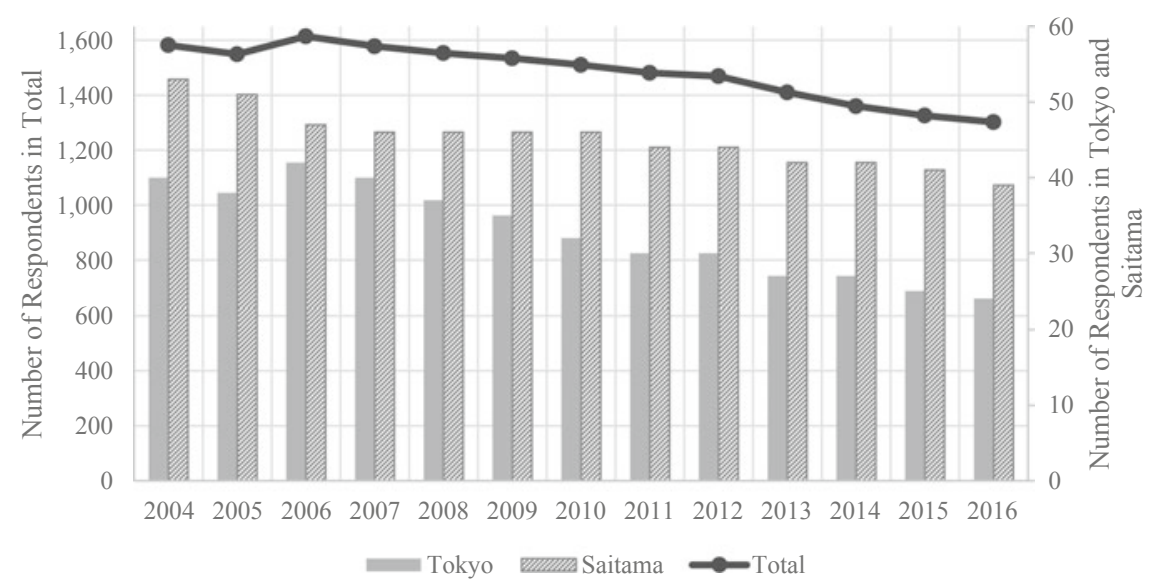

Fig. 1 Number of reporting facilities in the CSEC

to 1300 in 2016. Such a decreasing trend was also observed within Tokyo and Saitama. The closure of facilities and the integration of firms and/or facilities partially caused this trend. Such a trend implies that in Japan, the economic size of energy-intensive sectors has been diminishing over time. This finding may reflect the transition of the Japanese economy from being driven by the manufacturing sector to being driven by the service sector, as typical in many developed economies.

Figure 2 shows the trend of monthly average electricity consumption per facility, measured by thousand kWh, in five major prefectures: Saitama, Tokyo, Chiba, Kanagawa, Aichi, and Osaka. The electricity consumption in Tokyo and Saitama is shown

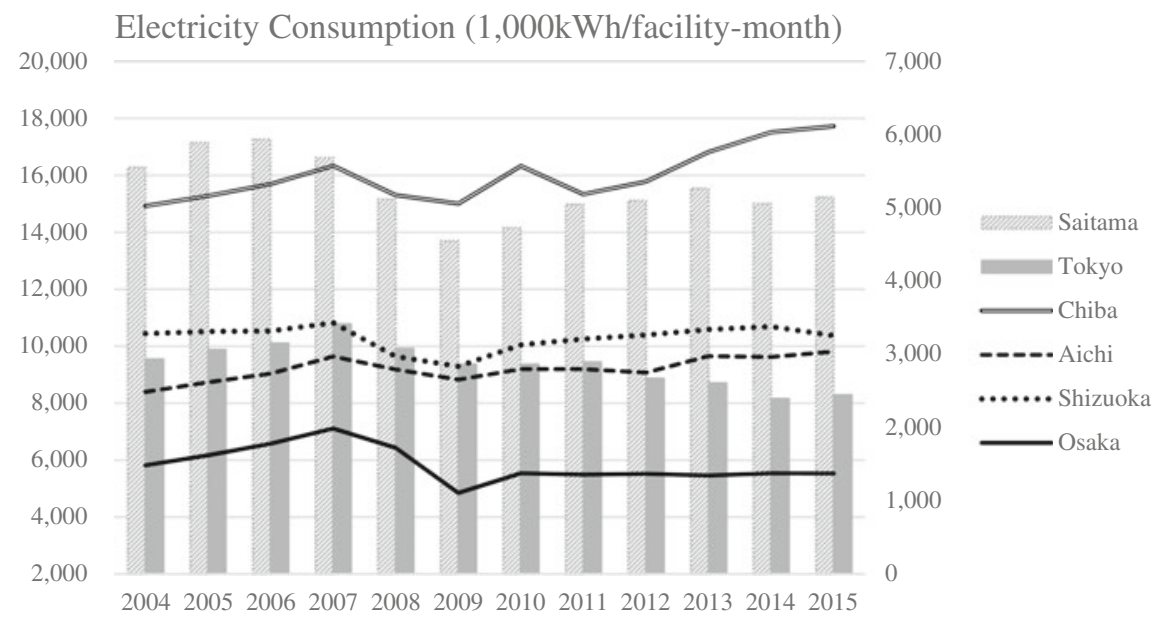

Fig. 2 Average monthly electricity consumption per facility by prefecture (the right axis is for Saitama and Tokyo and the left axis is for the other prefectures) 


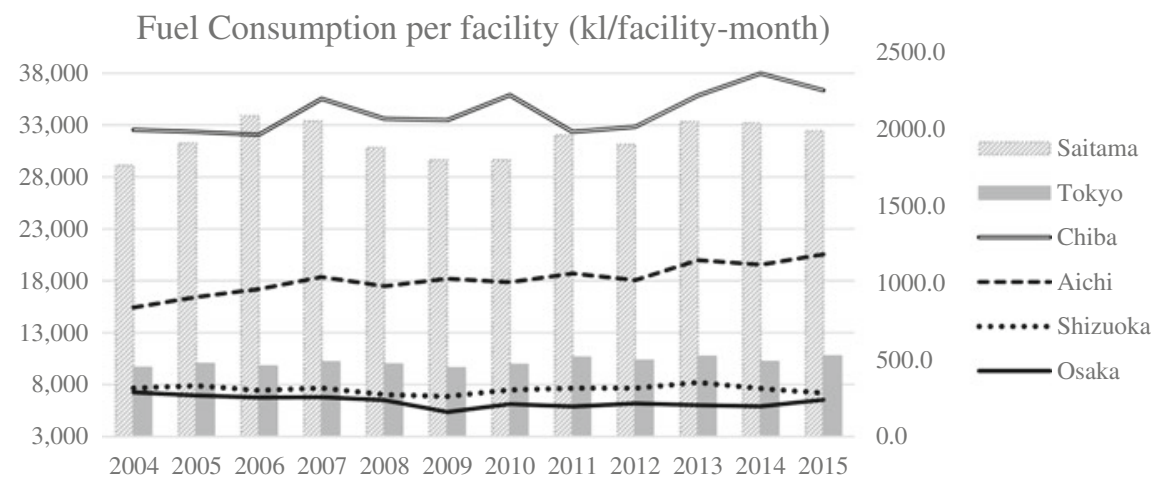

Fig. 3 Monthly average consumption of fossil fuel and steam, measured by crude oil equivalent, in transition

in bars (right axis), while that in the other prefectures is shown in line plots (left axis). The average electricity consumption peaked in 2007 , the year before the financial crisis. The decline in electricity consumption between 2007 and 2009 was relatively small in Tokyo. After 2009, consumption gradually recovered in Chiba, Aichi, Shizuoka, and Saitama, where manufacturing industries are relatively active, while consumption declined or remained constant in Tokyo and Osaka. This contradictory consumption pattern between Saitama and Osaka can be explained as follows. Saitama prefecture is closer to the capital of Japan, Tokyo. Therefore, compared to other regions, it may have faced a smaller impact on its economic activities. Additionally, the difference in the industrial structures of areas may affect the impact of the Tokyo ETS and/or technological innovations on electricity consumption.

Figure 3 displays the trends of fuel consumption (i.e., the sum of fossil fuels and steam) per facility-month by prefecture, measured in crude oil equivalent. ${ }^{3}$ Although the fuel consumption per facility in Chiba, Aichi, and Saitama moderately increased over time, the aggregate fuel consumption of all reporting facilities in each prefecture decreased (Fig. 4) due to the reduced number of facilities (Fig. 1). These observed trends may reflect the fact that small- and medium-sized facilities were more likely to close and drop out from the survey over time while large facilities remained, even with the recent stagnation in the manufacturing sector.

In addition to the drop in the number of reporting facilities, several other factors that may have driven these decreasing trends of fuel consumption. One is the effective environmental policies implemented by national and/or municipal governments. To improve energy efficiency, the manufacturing sector has been under environmental regulations since the 1970s, such as the Energy Saving Act (Arimura and Iwata 2015). Such regulations could reduce fuel consumption by improving energy intensity in advance of the implementation of the ETSs. Another possible factor is the increase in electricity prices. After the East Japan Great Earthquake in 2011, electricity prices

\footnotetext{
${ }^{3}$ For the calculation of crude oil equivalent, we use the conversion factors for each fuel and the criterion of $0.0258 \mathrm{kl} / \mathrm{GJ}$ of the Agency for Natural Resources and Energy of the METI (2015).
} 


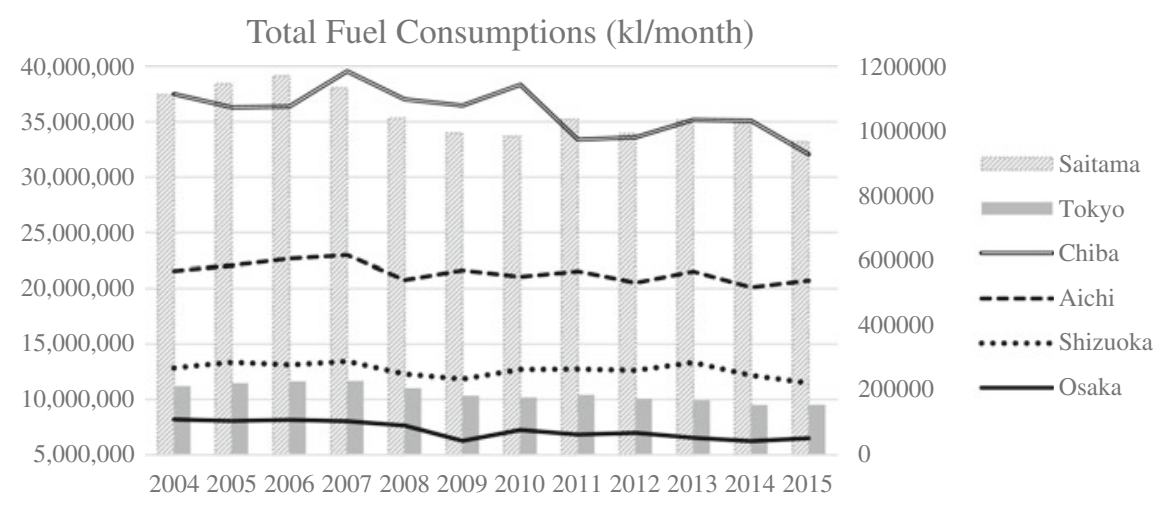

Fig. 4 Sum of the consumption of fossil fuel and steam, measured by crude oil equivalent, in transition

drastically increased in Japan due to the temporary shutdown of nuclear power plants (see Chap. 6). This sharp increase might have induced facilities in Japan to reduce their electricity consumption or substitute other fuels for electricity to manufacture. Additionally, the increase in the prices of other fuels, such as heavy fuel oil type A and natural gas, may have incentivized facilities to reduce their overall energy consumption. ${ }^{4}$ Under such scenarios, however, the electricity consumption per facility should decrease.

These trends also indicate that it is necessary to use nationwide and facility-level data to examine the effectiveness of the Tokyo ETS and Saitama ETS. There are three main reasons. First, the difficulty in introducing new production processes and technologies to comply with the regulations may be different across sectors. If a sector can adopt such changes at a lower cost than other sectors, then the sector may have reduced more emissions due to the ETSs. Moreover, this change is a facilitylevel decision; therefore, the facility is a relevant unit of analysis. Second, to control for the effects of other environmental policies, it is necessary to use information on facilities located in other regions. Finally, as shown in Fig. 3, Tokyo and Saitama have relatively low fuel consumption compared with other regions, which means that the ETSs may have potentially low impacts on the facilities in their locations. Our data set can provide a relevant control group and units to examine the impacts of the ETSs.

\footnotetext{
${ }^{4}$ The Energy Data and Modelling Center, (2019), "Handbook of Japan's \& World Energy \& Economic Statistics", The Energy Conservation Center, Japan.
} 


\section{Estimation Model and Results}

This section examines the causal effects of the Tokyo ETS and Saitama ETS on the energy consumption of facilities by fuel type and total energy consumption. Although Wakabayashi and Kimura (2018) and Chap. 6 find positive effects of the Tokyo ETS on the mitigation of aggregate $\mathrm{CO}_{2}$ emissions, the effects on the consumption of each fuel are still not clear. The ETSs may have incentivized regulated facilities to change their fuel mix to reduce emissions. However, do regulated facilities actually shift their energy consumption from dirty fuels to cleaner fuels? Regarding electricity, Chap. 6 and Arimura and Abe (2020) show that the Tokyo ETS has reduced electricity consumption in university and office buildings. Because such buildings in the service sector use electricity as their main energy source, the impacts of the ETS might have been greater than those in manufacturing sectors. What is the effect on electricity consumption in manufacturing sectors where facilities use more fossil fuels? To investigate these questions, we apply the difference-in-differences approach and estimate the following equation:

$\ln \left(\right.$ Fuel $\left._{i s t}\right)=\gamma$ TokyoET $S_{i s t}+\rho$ SaitamaET $S_{i s t}+\beta X_{i t}+\lambda_{s}+\eta_{t}+\mu_{i}+\varepsilon_{i s t}$

where $i$ denotes the facility, $s$ denotes the month and tenotes the year. Our sample period is from FY2004 to FY2014, which covers the period of Phase 1 of the ETSs.

The dependent variable, $\ln \left(F_{u e l} l_{i s t}\right)$, is the logarithmic value of a type of fuel consumed by facility $i$ during month $s$ in year $t$. For this analysis, we select electricity, heavy fuel oil, LPG, town gas and steam because of the relatively large amount of data on the consumption of these fuels. We also examine the aggregate consumption of energy produced from fossil fuels and steam as well as the power generation by cogeneration, waterpower, and other renewable energies. Under the ETSs, power generation from renewable energies can be excluded by calculating total $\mathrm{CO}_{2}$ emissions. Therefore, facilities may have an incentive to generate electricity themselves. ${ }^{5}$

TokyoET $S_{\text {ist }}$ and SaitamaET $S_{\text {ist }}$ are the dummy variables of interest; they indicate facility $i$ regulated under the Tokyo ETS and the Saitama ETS, respectively, during month $s$ in year $t$. Because the Tokyo ETS was introduced in April 2010, TokyoET $S_{\text {ist }}$ takes the value of one if and only if the time of the data is later than March 2010 and the facility is under the Tokyo ETS. Similarly, SaitamaET $S_{i s t}$ takes the value of one if and only if the time of the data is later than March 2011 and the facility is under the Saitama ETS. The parameters $\gamma$ and $\rho$ capture the impacts of the Tokyo ETS and the Saitama ETS, respectively, on the consumption of each fuel. We identify the regulated facilities under the ETSs by using official data sets

\footnotetext{
${ }^{5}$ For detailed information, see: A policy guideline issued by Tokyo Metropolitan Government (2015), https://www.kankyo.metro.tokyo.lg.jp/en/climate/cap_and_trade/index.files/TokyoCaT_ detailed_documents.pdf (accessed 2020-07-08).
} 
provided by the Tokyo metropolitan government and the Saitama government. ${ }^{6}$ In our samples, there are 42 reporting facilities in Tokyo and 60 reporting facilities in Saitama, of which 24 and 34 facilities are regulated under the Tokyo ETS and the Saitama ETS, respectively, for at least one year. ${ }^{7}$ The records of all 24 regulated facilities in Tokyo exist since the implementation of the Tokyo ETS, while the records of some of the 34 regulated facilities in Saitama appear at different periods during Phase 1. Additionally, a few regulated facilities in Saitama were exempted from the ETS during Phase 1, in which case, SaitamaET $S_{\text {ist }}$ takes the value of zero once the facility is exempted from the regulation.

Because the choice and quantity of energy consumption are not solely determined by the ETSs, we need to control for the effects of other factors that might affect energy consumption (such as the size of the facility, sector-specific production processes, temperature and the economic situation) to extract the pure effects of the ETSs. The control variables, $X_{i t}$, include the natural $\log$ of cooling-degree days and heatingdegree days to capture the effect of temperature ${ }^{8}$ and the natural $\log$ of electricity prices by ten regions. ${ }^{9}$ We also control for monthly fixed effects, $\lambda_{s}$, and yearly fixed effects, $\eta_{t}$, to capture the dynamic nationwide economic impact and the effect of sector-specific production processes, respectively; additionally, we control for facility fixed effects, $\mu_{i}$, to capture unobservable facility-specific effects such as facility size and architectural performance. Finally, $\varepsilon_{i s t}$ is the idiosyncratic error term.

One of the disadvantages of this survey is that it does not include information on economic activities such as outputs and the number of employees. This lack of information is one of the limitations of the data set used in this chapter.

Table 3 displays the summary statistics of fuel consumption and the control variables as real values from FY2004 to FY2015. We find that there are many zero or missing values. These values imply no reporting and/or no consumption of these fuels. In our analysis, missing values are excluded, and zero values are excluded by $\log$ transformation in the estimation. Fuel consumption shows right-skewed distributions. For instance, the annual electricity consumption ranges from $0 \mathrm{kWh}$ to

\footnotetext{
${ }^{6}$ Although the information has been continually revised, the lists of regulated facilities were obtained from the homepages of the local governments: https://www9.kankyo.metro.tokyo.lg.jp/koukai/ koukai.html (for Tokyo) and https://translation2.j-server.com/LUCSAIPREF/ns/tl.cgi/https://www. pref.saitama.lg.jp/a0502/keikakukouhyou.html (for Saitama).

${ }^{7}$ We used the name of the facilities and/or their address as identifiers.

${ }^{8}$ Cooling degree-days (Heating degree-days) are a proxy variable of the annual energy consumption required for cooling (heading) in each prefecture, which is defined as annual sum of the difference between daily average temperature and $24^{\circ}\left(14^{\circ}\right)$ for each day in which daily average temperature is hotter than $22^{\circ}$ (cooler than $14^{\circ}$ ) in each prefecture capital.

${ }^{9}$ Electricity was mostly provided to each facility by one of ten regional monopolistic power companies before the deregulation of the electric power industry in Japan in 2000. After the deregulation, it is difficult to identify the electricity supplier of each facility. We use the electricity prices of these power companies, calculated by dividing the annual profits from electricity sales by the quantities of electricity produced, as proxies for electricity prices, despite the possibility that facilities may contract with a different supplier.
} 
Table 3 Summary statistics

\begin{tabular}{l|l|l|l|l|l}
\hline Total energy consumption & Obs. & Mean & S.D. & Min & Max \\
\hline Crude oil equivalent (kl) & 217,734 & $14,001.26$ & $64,100.16$ & 0 & 1072,132 \\
\hline Crude oil equivalent (kl, w/o electricity) & 217,734 & $12,984.27$ & $61,870.95$ & 0 & 1030,758 \\
\hline $\begin{array}{l}\text { Electricity } \\
\text { Electricity (consumption) }\end{array}$ & 214,810 & $11,098.5$ & $3,0341.5$ & 0.0 & $471,615.0$ \\
\hline $\begin{array}{l}\text { Electricity (generation) } \\
\text { Other Fuels }\end{array}$ & 217,734 & 1701.6 & 9624.2 & -251.0 & $335,021.0$ \\
\hline Heavy fuel oil (A, B, and C) & 217,734 & 428.2 & 1918.0 & 0 & 166,384 \\
\hline Liquefied petroleum gas (LPG) & 217,682 & 355.1 & 3243.1 & 0 & 118,556 \\
\hline $\begin{array}{l}\text { Town gas } \\
\text { Steam }\end{array}$ & 217,494 & 267.2 & 1153.9 & 0 & 80,793 \\
\hline Control variables & 152,551 & $43,668.8$ & $125,122.3$ & 0 & 2023,363 \\
\hline Cooling-degree days & 217,734 & 404.5 & 139.8 & 10 & 1042.1 \\
\hline Heating-degree days & 217,734 & 1038.0 & 383.1 & 0.6 & 2653.9 \\
\hline Electricity price & 217,734 & 17.2 & 2.0 & 14.2 & 23.4 \\
\hline
\end{tabular}

Note This table shows facility-month-level summary statistics from April 2004 to March 2016. The Tokyo ETS dummy and the Saitama ETS dummy are excluded from the table. Zero values imply no reporting and/or no consumption of these fuels. We exclude missing values

471,615 thousand $\mathrm{kWh}$, with a mean of 11,101 thousand $\mathrm{kWh}$. Log transformation can partially overcome such skewness.

Table 4 summarizes the estimation results. Each column shows the results using a different dependent variable, i.e., $\ln \left(F u e l_{i s t}\right)$. We start from the impacts of the Tokyo ETS. Column [1] shows the results for electricity consumption, for which the estimate is -0.16 and statistically significant at the $5 \%$ level. This finding indicates that the Tokyo ETS reduced the electricity consumption of a facility by approximately $16 \%$. This estimate is much greater than the impacts on electricity consumption in the service sector shown by Arimura and Abe's (2020) and Chap. 6, i.e., a 6\% reduction for office buildings and a $5 \%$ reduction for university buildings.

Columns [2] to [5] show the results regarding other types of fuel, namely, steam, heavy fuel oil, LPG and town gas. We found that only steam (column 2) and LPG (column 4) were reduced by the Tokyo ETS, although the size of the impact seems rather large. On the contrary, the impacts on heavy fuel oil and town gas were not statistically significant. These results may have been caused by the small number of facilities under the ETS.

What was the aggregate impact of the Tokyo ETS? Column [6] shows the estimation results of the aggregated fuel consumption, while column [7] shows the results for all fuels except electricity. Column [6] shows that the total energy consumption was reduced by $12.3 \%$ due to the Tokyo ETS, and this result is statistically significant at the $10 \%$ level. Column [8] shows the impact of the Tokyo ETS on electricity 


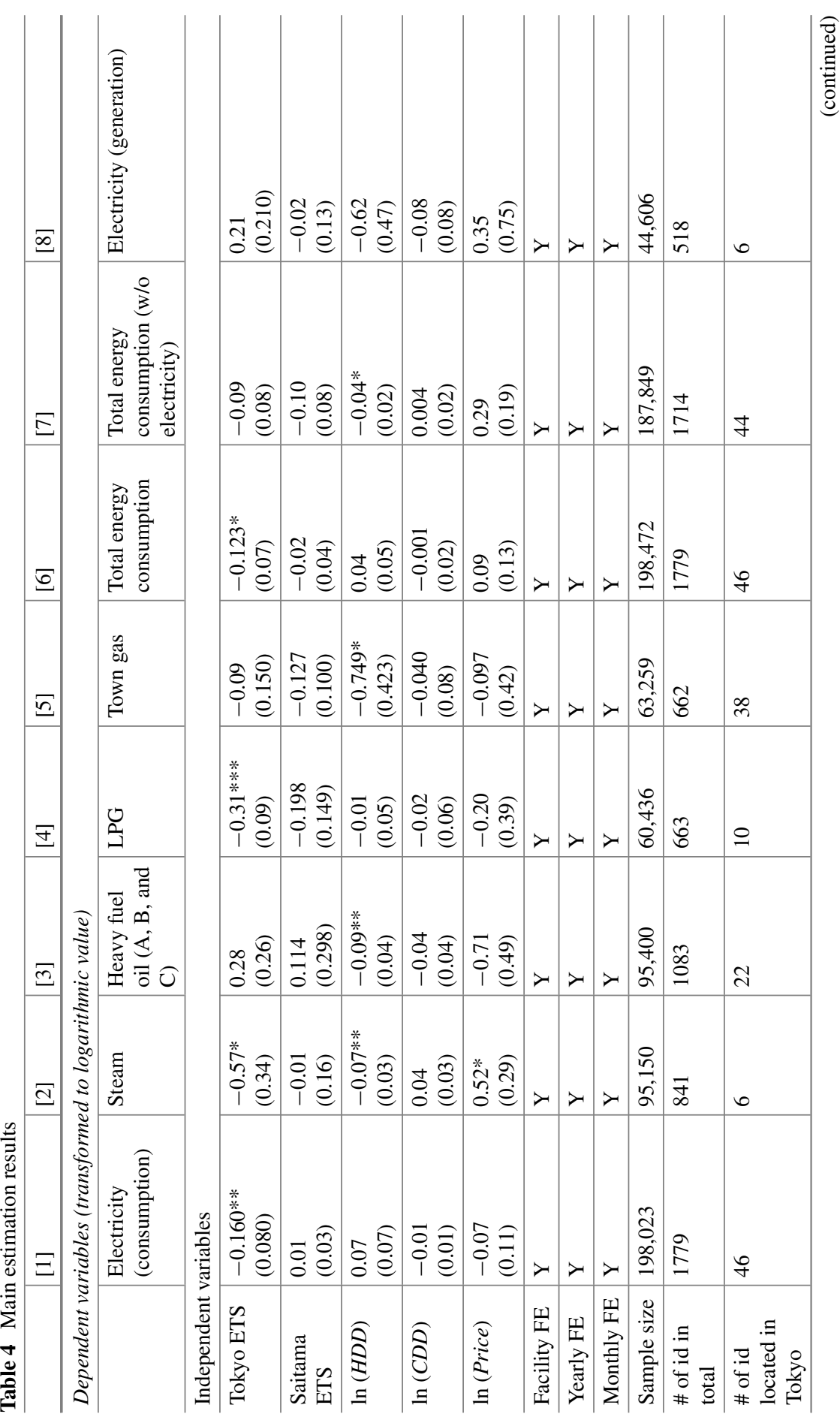




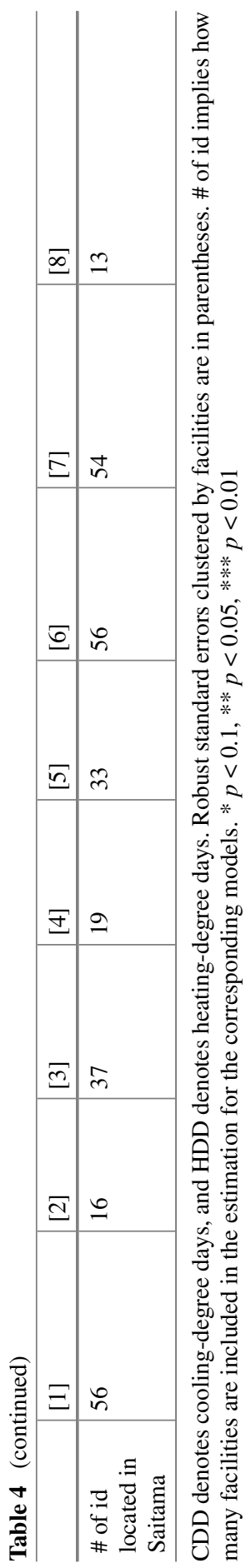


generation by renewable energies. However, we could not find evidence of the effects of promoting renewable energy usage/supply.

Our results may reveal the compliance behaviors of the regulated facilities under the Tokyo ETS. As we mentioned in the introduction, the regulated facilities have two options to comply with reduction requirements: reducing their emissions or purchasing emission allowances. Our findings imply that the regulated facilities choose the first option, with ninety percent of the regulated facilities performing emission reductions and only $10 \%$ obtaining additional permits to comply with the regulation. Thus, our estimation results are consistent with this behavior reported to the Tokyo government (Chap. 6). Notably, the facilities complied with their target by reducing electricity consumption.

Another finding from the estimation results is that reducing electricity consumption may be easier than reducing fossil fuel consumption. Reducing fossil fuel consumption may require some changes in production process technology, which requires an additional investment. For example, to reduce the consumption of fossil fuels, facilities may have to replace their overall equipment. In contrast, there are simple ways to reduce electricity consumption. For example, effective methods include the adoption of light-emitting diodes (LEDs) or the adoption of energy efficient appliances.

Our findings imply that facilities in the manufacturing sector in Tokyo achieved their target through reducing electricity consumption, such as in the case of university buildings (Chap. 6) or office buildings (Arimura and Abe 2020).

Unlike the results of the Tokyo ETS, we found no statistical evidence of impacts of the Saitama ETS on the consumption of any types of energy. However, such a result contradicts the results in Chap. 7 , which identified the significant effects on $\mathrm{CO}_{2}$ emissions in Saitama. One possible reason is that we use different samples in both the target industry and the control group. In its estimation, Chap. 7 uses information on all regulated facilities from all industries; moreover, it compares the facilities located in Saitama prefecture and Gunma prefecture. In contrast, we use only energyintensive sectors; that is, the number of regulated facilities we cover is relatively small. Additionally, there may be some heterogeneous impacts of the Saitama ETS that depend on the characteristics of the facilities in Saitama. For instance, large facilities may face more difficulties in reducing their fuel consumption.

One hypothesis that we wanted to test with this data set was whether facilities switch fuel from dirty fuel, such as heavy fuel oil, to cleaner fuel, such as town gas or electricity. Column [4] shows the estimation results for heavy oil. Neither the Tokyo or Saitama ETS reduced the consumption of heavy oil. Therefore, we could not identify a fuel switch from dirty fuel to cleaner fuel in this analysis.

All other control variables have no impact or little impact on the selected fuels. Regarding the electricity price, although a coefficient on electricity consumption is negative, it is not statistically significant. ${ }^{10}$ We note that the electricity price has a

\footnotetext{
${ }^{10}$ There are several possible reasons for this insignificant result. The first is the small number of treatments. The second is the fact that electricity is not the principal source of energy in the manufacturing sector. The third is the deregulation of the electric power industry, which leads
} 
positive and significant effect on the consumption of steam. This finding suggests that steam and electricity are substituted in the manufacturing process.

Finally, we compare our results with those found in the literature. We select the impacts of other ETSs, such as EUETS, Korean ETS (KETS), or Chinese pilot ETSs. Several empirical studies identified statistically significant effects of the ETSs. However, the sizes of the estimated impacts are mixed. In the case of the first phase (2015-2017) of the KETS, Jun et al. (2020) concluded that the burden of emission reductions has the impact of approximately $-30 \%$ on changes in carbon emissions in the manufacturing sector, however, it was not significant in the building sector, under the KETS. Moreover, Haijun et al. (2019) found that the regulated sectors reduced their carbon emissions by approximately 30\% under the Chinese pilot ETSs from 2013 to 2015. Dechezleprêtre et al. (2018) also revealed that the EU ETS reduced carbon emissions by $10 \%$ from 2005 to 2012. Similarly, Wagner et al. (2014) investigated the impacts of the EU-ETS on the energy composition of coal, oil, gas, and steam and found that the regulated plants reduced their share of coal by approximately $2 \%$ In the case of the EU-ETS, Chinese pilot ETSs, KETS, and Tokyo ETS, relatively larger impacts on $\mathrm{CO}_{2}$ reduction have been observed in the manufacturing sectors. Saitama ETS may have no effects in the manufacturing sectors. In officebuildings, the Tokyo ETS also has relatively larger impacts on carbon emissions while the KETS may have no effects. The impact of the ETSs on fuel or energy consumption varies among countries and sectors.

Moreover, in our analysis, there may be several limitations. First, we assume that the effects of the ETSs are constant over the sample period and all regulated facilities. However, such an assumption may not be realistic. Under the ETSs, regulated facilities can flexibly comply with their target. For example, if regulated facilities reduced emissions during the latter part of the compliance period, then the effects of the ETSs increased over time. Compliance behavior can also vary by industry-specific features. For instance, if replacing capital with more energy efficient capital is more difficult in one sector than in others, regulated facilities may postpone compliance with their target.

\section{Conclusions}

This chapter uses rich facility-level data from the CSES to analyze trends in the number of large facilities in the manufacturing sector and their energy consumption, and it also examines the impacts of the Tokyo ETS and the Saitama ETS on electricity, steam, and fossil fuel consumption.

\footnotetext{
to uncertainty with regard to the choice of electricity provider by each facility. The last is an equilibrium effect, where the reduction in the number of facilities in Tokyo and Saitama due to the implementation of the ETSs results in an increase in the unit cost of electricity production for power supply companies and, therefore, an increase in the electricity price.
} 
Our findings are summarized as follows. First, the number of targeted facilities was reduced from approximately 1600 in 2004 to 1300 by 2016. This finding may reflect a shift in the industrial structure from the manufacturing sector to the service sector, which leads to closures, temporary shutdowns, and manufacturing facility integration. In addition, the total consumption of fuel, such as electricity and other fuel types, declined in Tokyo and Saitama after 2006. The reduction in the number of manufacturing sector facilities is one of the reasons for this trend. These trends will contribute to the reduction of Japanese GHG emissions in the long run.

Second, our analysis demonstrated that the Tokyo ETS led to an approximately $16 \%$ reduction in electricity consumption in the manufacturing facilities, which is larger than the reduction in office buildings found by Arimura and Abe (2020). However, we could only find weak impacts on fossil fuel consumption. The Saitama ETS had no statistically significant impacts on the consumption of any type of fuel, which may be partly due to the insufficient number of facilities in Saitama for our analysis. We could not find any statistical evidence on shifting from dirty fuels to cleaner fuels under the ETSs. In addition, we could not identify statistically significant effects of the ETSs on electricity generation by renewable energies.

We compared our results with the findings in the literature on other ETSs. The impacts of the Tokyo ETS in the manufacturing sector were larger than that of the EU-ETS but smaller than that of the Chinese pilot ETS. Moreover, the impact of the Tokyo ETS was greater than that of the Korean ETS in office buildings. The impact of the ETSs varied among countries and sectors. What can explain these variations in the impact on emissions? Is it differences in the reduction targets, external economic conditions or other regulations? Such topics represent an important area of future work.

Our analysis has policy implications. The results provided in the previous chapters indicate that both the Tokyo ETS (Chap. 6) and Saitama ETS (Chap. 7) have heterogeneous effects across sectors and fuels. Our estimation results revealed a significant impact of the ETSs only on electricity in Tokyo but not on the consumption of other types of fuels in manufacturing sector. The weak impact of the ETS in Saitama may result from the voluntary nature of the Saitama ETS and the lack of penalty for violation. On the other hand, only a limited number of observations were available for the Saitama ETS, which may have influenced our empirical results for the Saitama ETS. Further research is needed on this point.

This study has other limitations in the empirical analysis as well. First, while our data set contains detailed information on facility-level fuel consumption on a monthly basis, it has no information on economic activities. Therefore, we could not investigate the impacts of the ETSs on the adjustment of the capital stocks of facilities. In the long run, facilities can adjust their capital stock through investment, which may alter their fuel mixes or the fuel types that they can use. Second, some facilities in electricity-intensive sectors, such as the chemical and steel industries, are exempted from paying the higher electricity prices that resulted from the feed-in tariff system. Such exempted facilities pay electricity prices that are lower than those observed in our data set. However, we could not identify those facilities and thus assume that they pay the same prices as other facilities. This difference in electricity 
prices may have caused some bias in our estimates. In future research, we would like to consider these points to more rigorously explore the impacts of the Tokyo ETS and Saitama ETS.

In the Paris Agreement, the Japanese government set a goal of reducing greenhouse gas emissions by $80 \%$ by 2050 . It looks like difficult to realize the target by ETS only. Even if the $16 \%$ reduction in Tokyo is significantly high, however, it is still not enough to achieve the goal. Moreover, the abatement cost has been increased generally, then the impacts of the ETS would decrease in the future. In a while, the Japan Center for Economic Research published a report claiming that this long-term target is feasible with a reasonable cost. ${ }^{11}$ The declining trends in the manufacturing sector and energy consumption discussed above help reduce emissions to a great extent. Considering such trends, the long-term goal of an $80 \%$ reduction may not be an unrealistic target in the future.

\section{References}

Arimura TH, Abe T (2020) The impact of the Tokyo emissions trading scheme on office buildings: what factor contributed to the emission reduction? Environ Econ Policy Stud

Arimura TH, Iwata K (2015) The $\mathrm{CO}_{2}$ emission reduction under the law concerning the rational use of energy: an empirical study of energy management in the Japanese hotel industry. In: Arimura $\mathrm{TH}$, Iwata K (eds) An evaluation of Japanese environmental regulations: quantitative approach from environmental economics. Springer, Berlin, pp 123-143

Agency for Natural Resources and Energy Ministry of METI (2015) Yearly report of the current survey of energy consumption

Bureau of Environment (2015) Tokyo cap-and-trade program for large facilities [Detailed Documents], Tokyo Metropolitan Government. Retrieved from https://www.kankyo.metro.tokyo.lg. jp/en/climate/cap_and_trade/index.files/TokyoCaT_detailed_documents.pdf (accessed 2020-0708)

Bureau of Environment (2019) Tokyo cap-and-trade program published information (in Japanese), Tokyo Metropolitan Government. Retrieved from https://www9.kankyo.metro.tokyo.lg.jp/kou kai/koukai.html (accessed 2020-07-08)

Dechezleprêtre A, Nachtigall D, Venmans F (2018) The joint impact of the European Union emissions trading system on carbon emissions and economic performance. OECD Economic Department Working Papers

Haijun Z, Maosheng D, Peng Z (2019) Analysis of the impact of China's emissions trading scheme on reducing carbon emissions. Energy Procedia 158:3596-3601

Jun SH, Kim JY, Oh H (2020) Evaluating mitigation performance of phase 1 of KETS. mimeo

Saitama Prefecture (2019) Planning and publication of implementation status. Retreived from https://translation2.j-server.com/LUCSAIPREF/ns/tl.cgi/https://www.pref.saitama.lg.jp/a0502/ keikakukouhyou.html (accessed 2020-07-08)

The Energy Data and Modelling Center (2019) Handbook of Japan's \& World Energy \& Economic Statistics, The Energy Conservation Center, Japan

The Japan Center for Economic Research (2019) Retrieved from https://www.jcer.or.jp/economicforecast/long-term (accessed 2020-07-08)

\footnotetext{
${ }^{11}$ This is also consistent with a prediction made by the Japan Center for Economic Research. For detailed information on the long-term predictions of the Japan Center for Economic Research, see the following URL: (https://www.jcer.or.jp/economic-forecast/long-term, accessed 2020-07-08).
} 
Wagner UJ, Muûls M, Martin R, Colmer J (2014) The causal effects of the European Union Emissions Trading Scheme: evidence from French manufacturing plants. In: Fifth world congress of environmental and resources economists. Instanbul, Turkey

Wakabayashi M, Kimura O (2018) The impact of the Tokyo Metropolitan Emissions Trading Scheme on reducing greenhouse gas emissions: findings from a facility-based study. Clim Policy 18(8):1028-1043; Economics 119(1):249-227

Naonari Yajima is a research associate at Waseda Institute of Political Economy, Waseda University in Japan. He is also a doctoral student at the Graduate School of Economics, Waseda University. He received his bachelors degree in Economics from Takasaki City University Of Economics (Valedictorian), and masters degree in Economics from Graduate School of Economics at Waseda University. He is the recipient of the Mitsubishi UFJ Trust Scholarship, 2017. His research interests are energy policy particularly focusing on voluntary environmental actions and organizational structure. He is currently working on empirical study that evaluates effects of Tokyo Emissions Trading Scheme, especially on changes in energy-saving behaviors by firms. He is a member of Society of Environmental Economics and Policy Studies, International Association for Environmental Economics and Japan Association of Political Economy.

Toshi H. Arimura is a Professor of Political Science and Economics and Director of the Research Institute for Environment Economics and Management at Waseda University in Tokyo. Prior to joining Waseda, he was a Professor at Sophia University in Tokyo and was a visiting scholar with George Mason University and Resources for the Future as a recipient of the Abe Fellowship. His research interests include climate change, energy policies, air pollution regulations and voluntary environmental actions. He has published his research in academic journals such as Journal Environmental Economics and Management, Journal of Association of Environmental and Resources Economics, Environmental and Resource Economics, Ecological Economics or Energy Policy. He is a coauthor of An Evaluation of Japanese Environmental Regulation: A Quantitative Approach from Environmental Economics (Springer 2015). Dr. Arimura holds a Ph.D. in economics from the University of Minnesota, an MSc in environmental sciences from the University of Tsukuba and a BA in history of science from the University of Tokyo. He has served on a number of Japanese government committees on environmental issues including the committees on carbon pricing (2018) and emission trading scheme (2010) of the environmental council under Ministry of the Environment. He is also a member of the Tokyo Metropolitan environmental council. He has served on advisory committees of local governments for emission trading schemes of Tokyo and Saitama. He has also been on editorial boards of academic journals such as Review of Environmental Economics and Policy, Agricultural and Resource Economics Review, Economics of Energy and Environmental Policy or Environmental Economics and Policy Studies $\circ$ Since 2018, Waseda University has choses him as one of 10 next generation core researchers. He is a recipient of SEEPS Outstanding Publication Award from Society for Environmental Economics and Policy Studies (Japanese Association of Environmental Economics and Policy) and the academic award from Society of Environmental Science, Japan.

Taisuke Sadayuki obtained Ph.D. in Economics from the University of Illinois at UrbanaChampaign in 2016 and joined the Research Institute for Environment Economics and Management (RIEEM) in 2018. Before joining Seijo University, he was an assistant professor at Waseda University. His main research interest is on empirical topics in urban and environmental economics. He proposed a new hedonic model in his paper published in Regional Science and Urban Economics. 
Open Access This chapter is licensed under the terms of the Creative Commons Attribution 4.0 International License (http://creativecommons.org/licenses/by/4.0/), which permits use, sharing, adaptation, distribution and reproduction in any medium or format, as long as you give appropriate credit to the original author(s) and the source, provide a link to the Creative Commons license and indicate if changes were made.

The images or other third party material in this chapter are included in the chapter's Creative Commons license, unless indicated otherwise in a credit line to the material. If material is not included in the chapter's Creative Commons license and your intended use is not permitted by statutory regulation or exceeds the permitted use, you will need to obtain permission directly from the copyright holder.

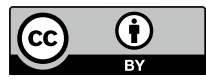

